\title{
China or South Korea: a comparative analysis of innovative development
}

\author{
Marina Reshetnikova*, Irina Pugacheva and Alina Evseevicheva \\ RUDN University, 117198 Moscow, Russian Federation
}

\begin{abstract}
Today, many countries understand the need to develop innovative ecosystems, come to the fore and become drivers of the global economy. For example, China and South Korea have identified the development of artificial intelligence (AI) as one of the main driving forces of the national economy at the present stage. The article considers the current position of countries in the world rankings of innovative development and the main directions of the development of artificial intelligence in these countries. Special attention is paid to the latest developments of South Korea and China in AI. The authors concluded that the development and commercialization of AI should become one of the most critical aspects of the future. With the right incentives and government support, South Korea and China can become leading countries in AI outpacing current leaders.
\end{abstract}

\section{Introduction}

The COVID-19 pandemic has significantly affected the economy of the entire world. The virus has had a substantial impact on the digitalization of the global economy in many countries. Digitalization is the primary driver of economic growth, and it is closely linked to the development of artificial intelligence technologies, the market volume of which may reach \$ 5.6-7 trillion by 2035 [1]. Such a scenario of market development indicates an increase in investment in this area.

AI allows organizations of various sizes to maintain and even increase their competitiveness, thanks to the automation of many business processes while improving the quality of products and increasing productivity. For example, during the pandemic, artificial intelligence made it possible to speed up the diagnosis of morbidity and introduce a system for monitoring compliance with the rules of physical distancing.

The Asian region is one of the fastest-growing and innovative in the world. It is home to more than a third of the world's unicorns, including the latest technologies. This article discusses the innovative development of the largest Asian countries in innovation: China and South Korea. The focus is on improving artificial intelligence technologies as the primary driver of the innovative development of these two states.

South Korea's GDP grew more than 200 times from 1960 to 2019, thanks to innovation [1]. In 2020, South Korea, for the first time, entered the top ten countries in terms of innovation development in the Global Innovation Index ranking and took 10th place [2]. The

\footnotetext{
${ }^{*}$ Corresponding author: reshetnikova-ms@rudn.ru
} 
Bloomberg Innovation Index held first place for six consecutive years, but in 2020 it lost its position to Germany. South Korea is even in the 2nd place after Singapore in the ranking of countries in terms of the density of robots per 10 thousand employees, indicating a high level of technological efficiency (868 robots, 2019) [3].

Even though South Korea has been one of the most innovative countries globally for many years, China does not give up its position and continues to increase innovations at an accelerated pace. China's race for technological leadership is intensifying against the United States but also against South Korea. In 2020, China was ranked 14th in the Bloomberg Innovation Index and 15th in the Global Innovation Index [2,3]. In the Ranking of artificial Intelligence Researchers (Nature Index), China is among the Top 50 countries leading in AI research in 2020 and is in second place, almost twice ahead of the UK (by 43\%). In this ranking, South Korea is in eighth place [4]. Consequently, there are differences in the innovative development and development of artificial intelligence technologies in these countries, but none should be discounted when determining leadership positions.

\section{Materials and methods}

The main methods used in this study were systematic and dialectical approaches to studying economic trends in the development of innovative technologies, including AI in China and South Korea.

For the analysis of quantitative indicators, methods of comparison and classification, media scanning, and crowdsourcing were used. The information is based on annual reference books published by the official resources of China and South Korea, statistical data of international publications devoted to innovative development, articles, and monographs. The main scientific provisions of this work were developed by the authors independently.

\section{Results}

Now, South Korea is the world leader in R\&D spending as a percentage of GDP. Total R\&D spending in 2020 was $4.3 \%$ of GDP [1].

The country has a well-organized and strong patent system, as evidenced by the World Intellectual Property Organization (WIPO) rating data. In 2019, South Korea ranked fourth globally in the number of patent applications and 1st in terms of the number of patent applications per unit of GDP [4].

South Korea owes this high performance to its government's systematic approach to research and innovation.

Recently, however, there has been a weak impact of government spending. Every year, the state's share of total investment in $\mathrm{R} \& \mathrm{D}$ falls despite their constant growth. The private sector ( about $80 \%$ of all R\&D spending) is starting to play an increasingly important role due to the pandemic. The growth rate and volume of private investment significantly exceed public funding $[4,5]$.

Projects aimed at developing the digital economy, robotics, blockchain technologies, big data, 5G networks, and artificial intelligence are currently receiving the most significant support. 


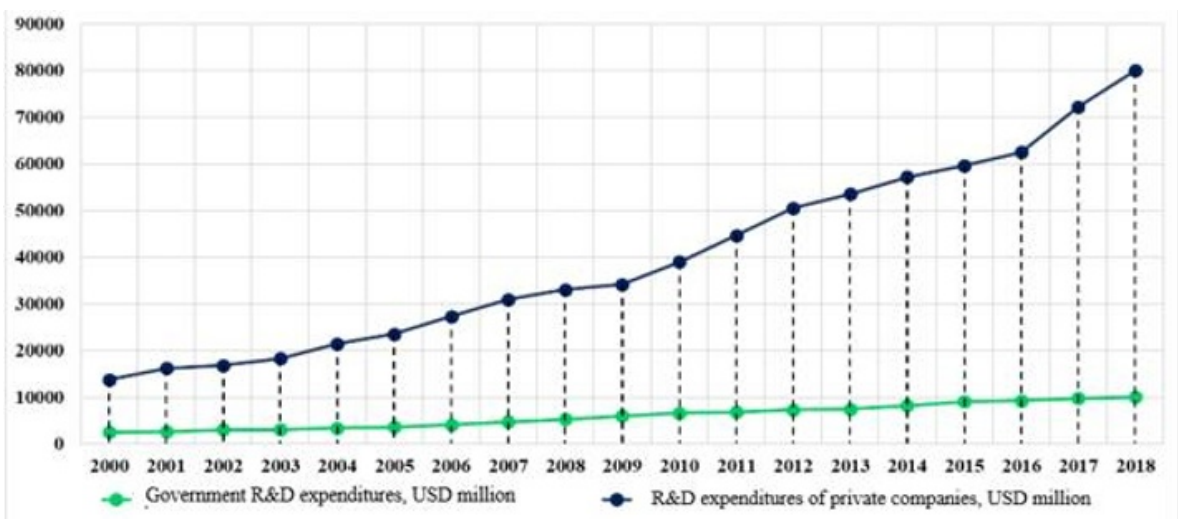

Fig. 1. Government and private R\&D expenditures in South Korea, USD million

The main goal of the AI development policy in China is to make China the world center of AI innovation by 2030 and define AI as "the main driving force of China's industrial modernization and economic transformation" [6].

The development of AI in China is carried out not only by scientists but also by large companies. Among them are the search giant Baidu, the ride-hailing service Didi, and the Tencent Corporation (the developer of the popular WeChat messenger in Asia). All these companies have their own AI technology research laboratories [7].

Toutiao, a Chinese startup, managed to secure a staggering $\$ 3.1$ billion in funding from investors such as Sequoia Capital. This figure pushed the company to the largest artificial intelligence launch in the world now, with a massive estimate of \$ 20 billion [3].

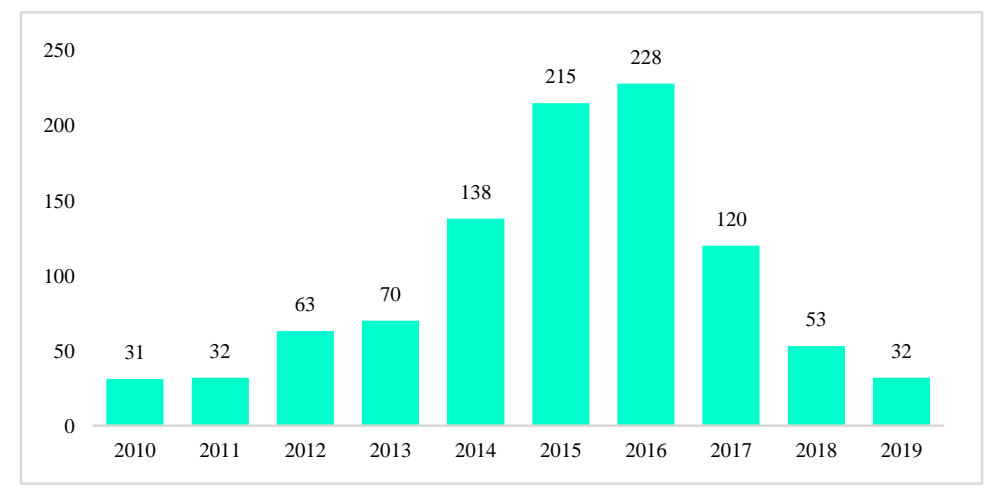

Fig. 2. Number of new AI startups in China, 2010-2019

The volume of investment in the Chinese AI healthcare sector is the highest globally. However, the country ranks 3rd in the world in terms of the number of studies in this field [8].

One of the specific AI applications in the medical field in China and South Korea is medical imaging. AI in medical imaging products is currently mainly used for screening diseases, especially cancer and chronic diseases [11]. 


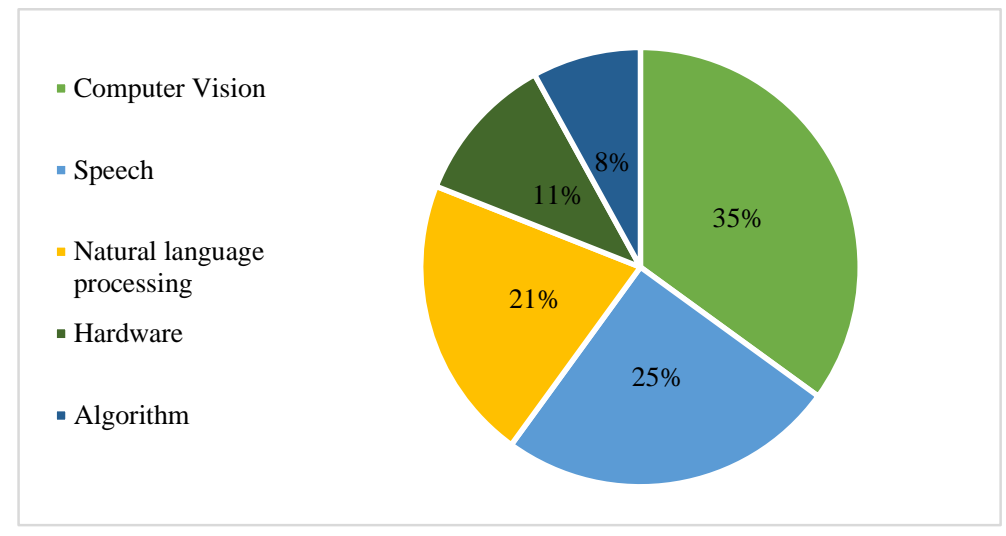

Fig. 3. China's AI market share by industry

Source: Compiled by the authors, data collected from [8-10]

To compare the innovation indicators of the two countries, the authors decided to choose the Bloomberg Innovation Index [3]. Bloomberg analyzes dozens of criteria and divides them into seven categories:

1. R\&D intensity: Research and development expenditure, as \% GDP;

2. Manufacturing value-added: MVA, as \% GDP and per capita (PPP);

3. Productivity: GDP and GNI per employed person age 15+ and $3 \mathrm{Y}$ improvement;

4. High-tech density: Number of domestically domiciled high-tech public companies such as aerospace and defense, biotechnology, hardware, software, semiconductors, Internet software and services, and renewable energy companies - as \% domestic publicly listed companies and as a share of the world's total public high-tech companies;

5. Tertiary efficiency: Total enrollment in tertiary education, regardless of age, as $\%$ the post-secondary cohort; gross graduation ratio of first-degree earners, the share of the labor force with the advanced level of education; annual new science and engineering graduates as $\%$ total tertiary graduates and as \% the labor force;

6. Researcher concentration: Professionals, including postgraduate $\mathrm{PhD}$ students, engaged in $R \& D$ per population;

7. Patent activity: Annual patent filings, patent grants, and patent-in-force, per population and GDP; $3 \mathrm{Y}$ avg growth of filings abroad and filings growth, per world total growth.

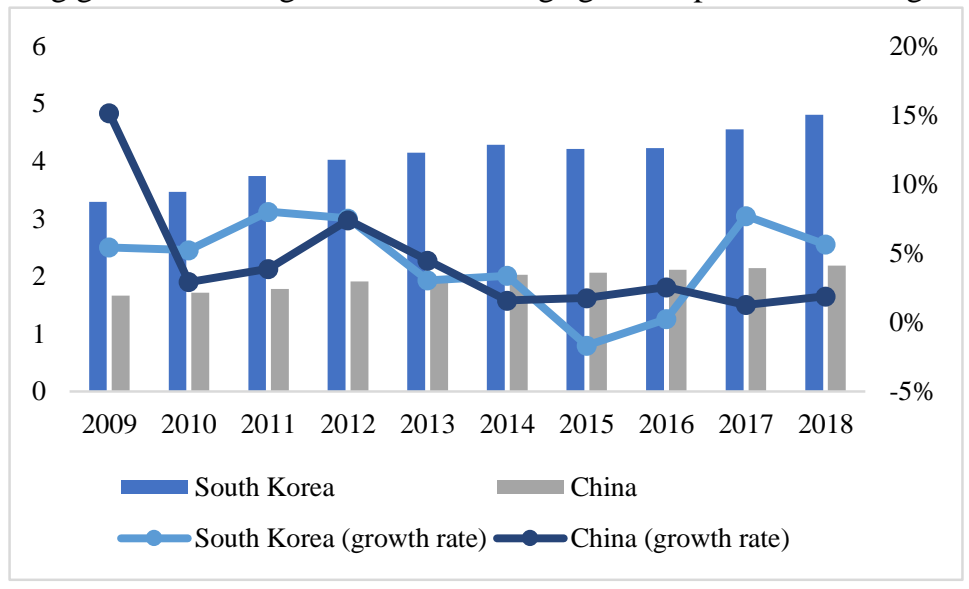

Fig. 4. R\&D intensity: Research and development expenditure, as \% GDP Source: Compiled by the authors, data collected from [1,2,4,8-10] 
Figure 4 shows that the intensity of R\&D development in South Korea is significantly higher than in China. For example, in 2018, the growth rate for this indicator was recorded in South Korea at 5.6\%, while in China, this indicator is less than 2.2 times (the growth rate is $1.9 \%$ ).

GDP and GNI per employed person aged 15 also differ in the two countries. In 2019, South Korea recorded a value of this indicator 27 times higher than in China (Figure 5). However, it is worth noting the high rate of productivity growth in China $(6.5 \%, 2019)$, which suggests that the level of productivity in innovation is growing at an accelerated pace and in a few years may catch up with South Korea, without taking into account changes in GDP. Otherwise, China will continue to lag.

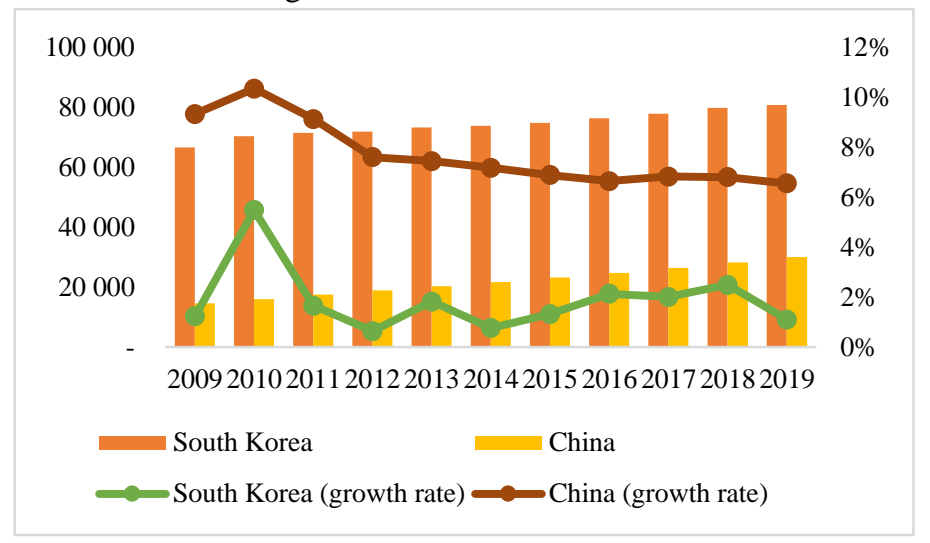

Fig. 5. Productivity: GDP and GNI per employed person age $15+$ and $3 \mathrm{Y}$ improvement Source: Compiled by the authors, data collected from [1,2,4,8-10]

Figure 6 shows the dynamics of the value-added indicator as a percentage of GDP and per capita. We can see that the value-added in South Korea is much greater, while before 2017, the value in \% of GDP was higher than South Korea, and now this figure is almost equal (25.3\% - South Korea, 26.8\% - China). Thus, this indicator is influenced not only by the output of innovative products but also by GDP and the demographic situation in the countries.

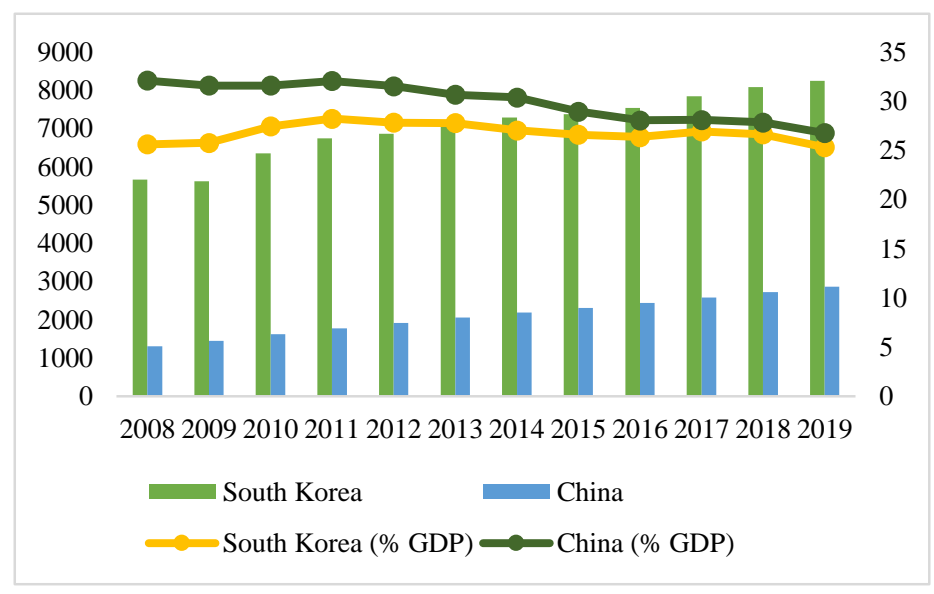

Fig. 6. Manufacturing value-added: MVA, as \% GDP and per capita (PPP)

Source: Compiled by the authors, data collected from [1,2,4,8-12] 
Interestingly, despite the high research concentration, South Korea is significantly inferior to China in patent activity.

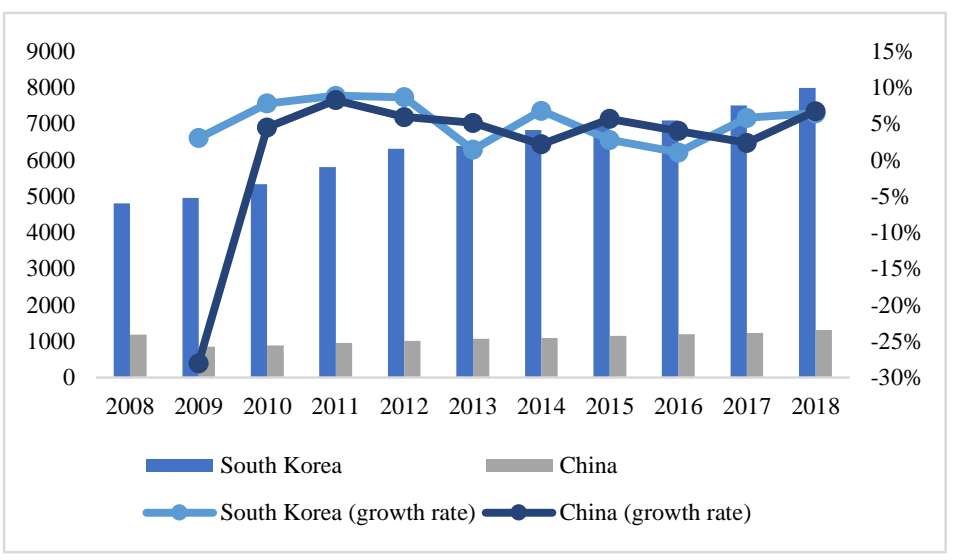

Fig. 7. Researcher concentration: Professionals, including postgraduate $\mathrm{PhD}$ students, engaged in $\mathrm{R} \& \mathrm{D}$ per population

Source: Compiled by the authors, data collected from [2,4,8-10]

Figure 7 clearly shows how the 2008 crisis affected the research concentration index in China (-28\% compared to 2008), while it did not affect South Korea as much, and the indicator even increased by $3 \%$. In subsequent years, the decline in the indicator is not observed in either China or South Korea; by 2018, the growth rate of the indicator is almost identical (6.7\% and $6.4 \%$, respectively).

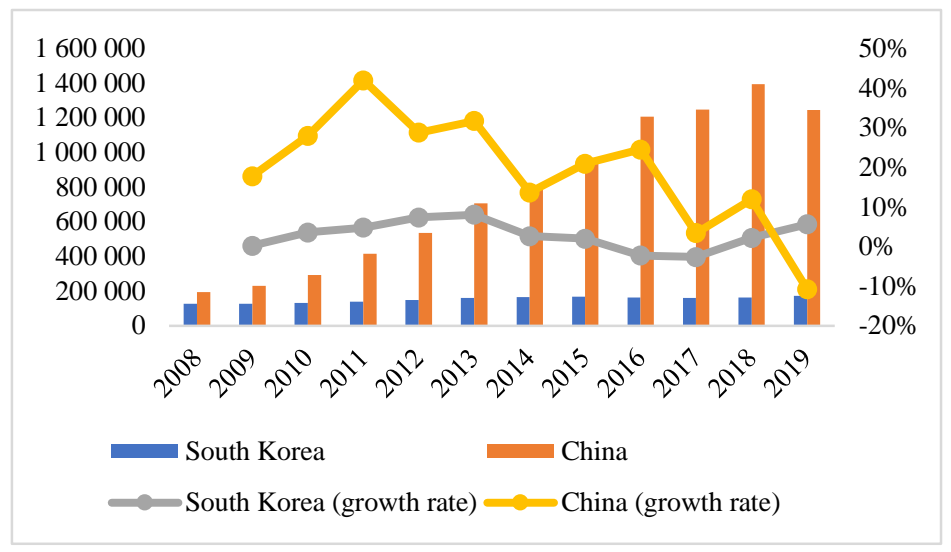

Fig. 8. Patent activity: Annual patent filings, patent grants, and patent-in-force, per population and GDP; $3 \mathrm{Y}$ avg growth of filings abroad and filings growth, per world total growth

Source: Compiled by the authors, data collected from [2-4,8-10]

The patent activity indicator is the only Bloomberg indicator. China shows a significant growth in contrast to a competitor whose patent activity remains roughly at the same level from 2008 to 2019 (Figure 8). In 2016-2017, the growth rate of patent activity in South Korea was negative, but since 2017 , there has been a positive trend. The peak of patent activity in China occurred in 2011, after which the growth rate began to fall cyclically, and in 2019 it fell to a value of $-10.8 \%$. 


\section{Discussion}

The innovation development strategies of both countries are closely linked to the development of AI technologies, and governments try to support their states through funding for research and development [13]. For example, in South Korea, over the next ten years, from 2020 to 2029, the government intends to invest 1 trillion won ( $\$ 856.5$ million) in this industry, as well as create a venture fund (more than 5 trillion won ( $\$ 4.2$ billion)) for startups engaged in AI development [14]. The South Korean government's goal is to become a leader in the global market for chips used to create AI technologies.

AI innovations in medicine can be divided into three broad categories: image analysis and diagnostics, intelligent voice transcription and integrated prediction, and prevention and treatment based on patient metadata [15].

In South Korea, most artificial intelligence companies focus on the first category - medical image analysis and diagnostics. Between 2017 and 2019, 13 medical AI systems were developed in various fields [14].

In a competitive market, even a $1 \%$ reduction in accuracy is essential. As for intelligent voice transcription, South Korean startups have an additional hurdle that their Chinese counterparts do not face. Most South Korean medical staff use English and Korean, and the situation is compounded by the fact that the pronunciation of non-Korean terms is often inaccurate. Therefore, it was difficult for South Korean programs to achieve 95\% accuracy, which is achieved by similar products in the United States [16].

Post-COVID-19 recovery plans to lean heavily on AI \& wireless telecommunications technology to provide economic stimulus. AI \& $5 \mathrm{G}$ technology is already being heavily trailed within South Korea [17].

China is also the most significant market globally for educational technologies, and AI developments help in their implementation. An example of applying AI to online learning is creating the Yuanfudao platform (Yuantiku), which focuses on learning and includes AIenabled virtual classrooms, live learning, and homework support apps [18,19].

China had unprecedented advances in AI technology during the coronavirus outbreak. These technologies were used to fight the disease and diagnose it. China has also used AI technology for public health purposes, such as disinfection robots and real-time maps showing the location of active infections. As a result of the pandemic, AI received additional government support and investment. The Chinese company HY Medical, which uses AI in medicine and Huawei Cloud, has created an open AI platform EIHealth for diagnosing coronavirus based on CT results in 25 seconds with up to $95 \%$ confidence. The platform operates in 20 countries (Great Britain, Malaysia, Thailand, Panama, Mexico, Chile, Ecuador)[20-22] .

The pandemic has fostered close cooperation between government agencies and China's major technology companies to ensure that the virus is quickly and effectively controlled. A striking example is the "QR-code of health" system developed by the Chinese technology giants WeChat and Alipay. It allows tracking the Chinese residents and signaling possible contacts with infected people based on data from the electronic state platform National Online Government Service Platform (NOGSP), which is under the State Council of the People's Republic of China. The Alipay Health Code system has demonstrated its effectiveness and allowed China to reduce the number of infected COVID-19 as much as possible [22].

The closure of most stores, cinemas, and restaurants led to the emergence of new platforms for the sale of goods and services. The Chinese Douyin platform became one of the largest, thanks to which Chinese residents sold their agricultural products, machinery, electronics, and other goods and services in self-isolation. 
The Sino-American confrontation in the field, which accelerated import substitution in China, served as another impetus for the emergence of new AI technologies in 2020. In April 2020, the BSN platform's official launch, a blockchain network for interaction between international companies and individuals, took place. The Chinese blockchain network will increase the level of data security when making transactions and transactions in cryptocurrency. Such large private enterprises in China as China Mobile and China UnionPay, and state-owned companies already cooperate with this platform.

\section{Conclusion}

Today it is more apparent than ever that there has been a change in the entire world economic paradigm of a catch-up development trend. Some peripheral states have successfully implemented this strategy. It allowed them to quickly achieve high economic growth through the industrialization of national economies. The innovative leading countries had a win-win moment by moving environmentally harmful and not modern national territories. At the same time, their dominance in the high-tech sector remained.

China is the primary winner in the implementation of the catch-up strategy. In a historically short period, from a backward country in which life expectancy did not exceed 40 years, it grew into the world's second-largest economy while remaining in the shadow of innovative leaders.

Now, this shadow weighs in China. It no longer wants to be a global factory but a "scientific and technological superpower." The global dominance in AI will ensure this. By consistently implementing the state policy for a new generation of AI since 2017, Beijing has confidently moved into second place in development, behind only the United States [23].

Its rapid success could not but excite the leading competitor. Silicon Valley was getting nervous. The strategic situation in global innovation has changed as the competition is getting more rigid. This explains the two tech giants' actions: increased protectionism in the domestic market in China and the growth of prohibitive measures against Chinese companies in the United States.

Experts predict that the AI industry will "take off" in the next ten years. The development and commercialization of AI should be one of the most critical aspects of the future of medical science and technology. With the right incentives and government support, South Korea and China can become leading examples in AI.

The article was prepared with the financial support of the RUDN University Economic Faculty, project № 060326-0-000.

\section{References}

1. The World Bank, https://data.worldbank.org/

2. Global Innovation Index, https://www.wipo.int/

3. Bloomberg, https://www.bloomberg.com/europe

4. WIPO World Intellectual Property Indicators 2019, https://www.wipo.int/

5. B. Hwang, E. Bae, H. Hong, D. Kim, JOItmC, 5 (2019).

6. M.S. Reshetnikova, Global Economic System: Evolutional Development vs. Revolutionary Leap, 198, 2064 (Springer International Publishing, 2021).

7. O’Meara, Nature 572 (2019).

8. IDC worldwide Artificial Intelligence Spending Guide - Forecast 2020, https://www.idc.com/

9. WIPO Technology Trends 2019: Artificial Intelligence. (2020), https://www.wipo.int/ 
10. World Intellectual Property Organization, https://www.wipo.int/

11. McKinsey. The state of AI in 2020 (2020).

12. R. Shimonski, AI in Healthcare: How Artificial Intelligence Is Changing IT Operations and Infrastructure. (Wiley, 2021).

13. UNESCO Institute for Statistics, http://data.uis.unesco.org/

14. J. Ding, Deciphering China's AI Dream (University of Oxford, 2018)

15. Enhancing dynamism in SMEs and entrepreneurship in Korea, 1510 (2018)

16. G.S. Panwar, Machine Learning Trends to Watch Out in 2020 and 2021 (2020)

17. C. Fang, C. et al. Deep learning for predicting COVID-19 malignant progression (2020)

18. C. Langmann, Robotic Process Automation (RPA) - Study on Characteristics of Successful RPA Implementations (University of Applies Science, 2021)

19. T. Boobier, AI and the Future of Banking (Wiley, 2020).

20. AI in the healthcare sector in China: current trends and applications, https://daxueconsulting.com/ai-healthcare-china/

21. Sumit. IJMTST 6, (2020).

22. Z. Li, X.Wang, T. Zhang, 5G+: How 5G Change the Society (Springer Singapore, 2021).

23. R. Liao, China's national blockchain network embraces global developers (2021).

24. M. Reshetnikova, Utopía y praxis latinoamericana, 25(2), (2020) 